\title{
Predictive risk factors for worse outcomes in COVID-19 patients with different clinical features at baseline
}

Elisabetta Schiaroli ${ }^{1}$, Anna Gidari ${ }^{1}$, Giovanni Brachelente ${ }^{2}$, Sabrina Bastianelli ${ }^{1}$, Alfredo Villa ${ }^{2}$, Carla Ferri², Daniela Francisci ${ }^{1}$

\author{
${ }^{1}$ Clinic of Infectious Diseases, Department of Medicine, University of Perugia, Perugia, \\ Italy \\ ${ }^{2}$ Clinical Pathology and Hematology, Santa Maria della Misericordia Hospital, Perugia, \\ Italy \\ Arch Med Sci \\ DOI: https://doi.org/10.5114/aoms/130374 \\ Copyright $\odot 2021$ Termedia \& Banach
}

\begin{abstract}
Introduction: COVID-19 is characterized by a wide range of clinical expression and by possible progression to critical illness and death. Therefore it is essential to identify risk factors predicting progression towards serious and fatal diseases. The aim of our study was to identify laboratory predictive markers of clinical progression in patients with moderate/severe disease and in those with acute respiratory distress syndrome (ARDS).

Material and methods: Using electronic medical records for all demographic, clinical and laboratory data, a retrospective study on all consecutive patients with COVID-19 admitted to the Infectious Disease Clinic of Perugia was performed. The $\mathrm{PaO}_{2} / \mathrm{FiO}_{2}$ ratio (P/F) assessment cut-off of $200 \mathrm{~mm} \mathrm{Hg}$ was used at baseline to categorize the patients into two clinical groups. The progression towards invasive ventilation and/or death was used to identify critical outcome. Statistical analysis was performed. Multivariate logistic regression analysis was adopted to identify risk factors of critical illness and mortality.

Results: In multivariate logistic regression analysis neutrophil/lymphocyte ratio (NLR) was the only significant predictive factor of progression to a critical outcome $(p=0.03)$ and of in-hospital mortality $(p=0.03)$. In ARDS patients no factors were associated with critical progression. Serum ferritin $>1006 \mathrm{ng} / \mathrm{ml}$ was the only predictive value of critical outcome in COVID-19 subjects with moderate/severe disease $(p=0.02)$.

Conclusions: Neutrophil/lymphocyte ratio and serum ferritin are the only biomarkers that can help to stratify the risk of severity and mortality in patients with COVID-19.
\end{abstract}

Key words: neutrophil/lymphocyte ratio, serum ferritin, COVID-19, predictive factors.

\section{Introduction}

Coronavirus disease 2019 (COVID-19), caused by SARS-CoV-2, appears with a wide range of clinical expression: asymptomatic, mild, moderate, severe and critical features which can progress to death [1].

Most patients with SARS-CoV-2 have a mild disease and present common symptoms such as fever, cough, and fatigue [2]. Usually, they are not hospitalized. Other patients can show a moderate illness (fever and pneumonia), severe pictures (pneumonia with hypoxemia, $\mathrm{SpO}_{2}<92 \%$ ), or critical forms with acute respiratory distress syndrome (ARDS), viral sepsis and so on.

\author{
Corresponding author: \\ Elisabetta Schiaroli MD \\ Clinic of Infectious Diseases \\ Department of Medicine \\ University of Perugia \\ Hospital "Santa Maria della \\ Misericordia" \\ Piazzale Menghini \\ 1 - 06156, Perugia, Italy \\ Phone: +39-075-5784375 \\ Fax: +39-075-5784346 \\ E-mail: \\ elisabetta.schiaroli@unipg.it
}


It is worth noting that the clinical course is characterized by a first stage in which viral replication predominates, a second with pulmonary involvement, and a third one in which systemic hyper-inflammation prevails. Severe and fatal forms are the final stage of viral infection progression with which the host' $s$ inflammatory and immunological response is associated [3]. However, only a small number of infected people progress to severe and critical forms with ARDS, multiple organ failure and death and, up to now, differences in pathogenesis between asymptomatic, mild and severe illnesses in COVID-19 patients are unknown, although age and comorbidities are factors associated with a more severe evolution [4-7]. Therefore, it is crucial to identify clinical and laboratory predictors of severe and fatal forms right away, in order to provide, apart from antiviral therapies, further interventional drugs aimed at preventing the possible hyperinflammatory phase that leads to ARDS, cardiac failure, hypercoagulation, viral sepsis and death.

The aim of our study was to analyze clinical characteristics and laboratory biomarkers in patients with COVID-19 at hospital admission in order to define which parameters can discriminate between those who are at a higher risk of developing critical vs. non-critical forms of the disease, as well as those who are less likely to survive.

\section{Material and methods}

We performed a retrospective study on all consecutive patients admitted to the Infectious Disease Clinic of Perugia between March 16 and May 5 , 2020 and tested positive for SARS-CoV-2.

Respiratory samples (nasopharyngeal swabs, sputum, tracheal aspirate, or bronchoalveolar lavage, BAL, fluid) were obtained from patients at admission and after 24 hours and they were tested for SARS-CoV-2 RNA using a commercial reverse transcriptase real-time PCR assay (RT-PCR assay, Allplex 2019-nCoV Assay, Seegene, Seoul) and/or with the Xpert Xpress SARS-CoV-2 (Cepheid).

Demographic and medical history, the presence of $\geq 2$ comorbidities (hypertension, coronary heart disease, diabetes, chronic obstructive lung disease, chronic kidney diseases, carcinoma and autoimmune diseases), clinical data (fever, cough, dyspnea) and laboratory and infection biomarkers, including blood routine, biochemistry, coagulation function, serum ferritin and $C$ reactive protein (CRP), were obtained for each patient after admission. The presence of dyspnea (respiration rate $\geq 24$ times/min), radiological characteristics of pneumonia, oxygen saturation $\left(\mathrm{SpO}_{2}\right)$ in resting state, arterial partial pressure of $\mathrm{O}_{2}\left(\mathrm{PaO}_{2}\right)$ and the fraction of inspired oxygen $\left(\mathrm{PaO}_{2} / \mathrm{FiO}_{2}\right)$ ratio $(\mathrm{P} / \mathrm{F})$ were assessed in each patient, highlighting those who, at baseline, had $\mathrm{PaO}_{2} / \mathrm{FiO}_{2}$ ratio $<200 \mathrm{~mm} \mathrm{Hg}$.
Indeed, the P/F cut-off assessment of $200 \mathrm{~mm} \mathrm{Hg}$ was used at baseline to distinguish two categories of patients: those with a $\mathrm{P} / \mathrm{F}<200 \mathrm{~mm} \mathrm{Hg}$ indicating moderate/severe ARDS [8] and suggesting an advanced disease with an important inflammatory component and those with a P/F $\geq 200 \mathrm{~mm} \mathrm{Hg}$, indicating a less advanced illness.

The progression of the disease in our cohort was analyzed using two different outcomes: critical COVID-19 illness and in-hospital mortality. We defined critical COVID-19 illness as a composite of admission to the intensive care unit (ICU), invasive ventilation or death as adopted in previous studies $[9,10]$.

Furthermore, patients with $\mathrm{P} / \mathrm{F} \geq 200 \mathrm{~mm} \mathrm{Hg}$ and with $\mathrm{P} / \mathrm{F}<200 \mathrm{~mm} \mathrm{Hg}$ at hospital admission were analyzed separately to individuate predictors of critical COVID-19 in both groups.

The demographic and clinical information, laboratory results, and outcome data were extracted from electronic medical records, collected in an Excel file for processing and compared between critical and non-critical illness and survivors vs. non-survivors. Statistical analysis was performed.

The study was approved by our local ethics committee and was conducted according to the Declaration of Helsinki.

\section{Statistical analyses}

Continuous variables were summarized as median with the respective interquartile range (IQR) or mean with the respective standard deviation (SD). Categorial variables were represented as percentage of cases.

Differences between groups were determined using the Mann-Whitney test, Student's $t$ test, or the $\chi^{2}$ test as appropriate. Statistical significance was determined as $p<0.05$.

Subsequently, multivariate logistic regression analysis was performed to identify risk factors of critical illness and mortality. Variables from the univariate analysis that showed a significant correlation with the outcome were included in the multivariate logistic regression analysis.

Continuous variables showing non-homogeneous data were transformed into categorical and then included in the multivariate logistic regression. To achieve this, performance of the single variable was evaluated by receiver operating characteristic (ROC) curve analysis. Subsequently, the most appropriate cut-off value was determined by calculating the Youden index. It corresponds to a point on the ROC curve with the highest vertical distance from the $45^{\circ}$ diagonal line [11].

The goodness of fit of the model was assessed with the Hosmer-Lemeshow test $(\mathrm{HL})$.

SPSS software version 25.0 (SPSS Inc., Chicago, IL, USA) was used for statistical analysis. 


\section{Results}

Seventy-nine adult patients with COVID-19 were admitted to the Infectious Disease Clinic of Perugia between March 16, and May 5, 2020. The median age was 65.5 years (IQR 32.2-87.6), most patients were male $(83.5 \%)$ and 2 or more comorbidities were present in $22.7 \%$ of all patients. High blood pressure was the most frequent comorbidity (44.3\%). Upon admission, fever, dyspnea and pneumonia were present in $93.6 \%, 51.9 \%$ and 97.5\%, respectively (Table I).

At baseline 32/79 patients had a $P / F<200 \mathrm{~mm} \mathrm{Hg}$ and 22 were admitted to the ICU during hospitalization, whereas $47 / 79$ had a $P / F \geq 200 \mathrm{~mm} \mathrm{Hg}$ and 21 needed invasive ventilation during hospitalization ( $p=0.06$, OR 2.7 (1.06-6.9)). The patients showed elevated median values of lactate dehydrogenase (LDH), serum ferritin, CRP, D-dimer and fibrinogen. Median values of the laboratory parameters are shown in Table I.
Considering the two groups of patients with $\mathrm{P} / \mathrm{F} \geq 200 \mathrm{~mm} \mathrm{Hg}$ and $<200 \mathrm{~mm} \mathrm{Hg}$, upon admission dyspnea was observed in $49 \%$ and $59 \%$, median NLR was 6.8 and 12.2, and median ferritin was $784 \mathrm{ng} / \mathrm{ml}$ and $990 \mathrm{ng} / \mathrm{ml}$ respectively.

\section{Critical illness}

Forty-three patients (54.4\%) showed a critical course of COVID-19 illness with progression towards invasive ventilation. The comparison of characteristics, laboratory and infection biomarkers between critical and non-critical illness upon admission is shown in Table I.

In the univariate analysis the median values of white blood cell (WBC) count, NLR, LDH, serum ferritin, CRP, procalcitonin (PCT) and D-dimer were significantly different between critical vs. non-critical patients $(p=0.006 ; p<0.0001 ; p=0.001$; $p=0.019 ; p=0.009 ; p<0.0001$ and $p=0.017$ respectively). For the multivariate analysis we included:

Table I. Demographic, clinic and laboratory characteristics of total patients with and without progression

\begin{tabular}{|c|c|c|c|c|}
\hline \multirow[t]{2}{*}{ Parameter } & \multirow[t]{2}{*}{ Total population } & \multicolumn{2}{|c|}{ Critical illness } & \multirow[t]{2}{*}{$P$-value } \\
\hline & & Yes & No & \\
\hline$N(\%)$ & 79 & $43(54.4)$ & $36(45.6)$ & \\
\hline Age [years], mean (SD) [range] & $65.5(10.6)[32.2-87.6]$ & $65.7(9.2)[46.7-87.6]$ & $65.3-12.1[32.2-84.8]$ & 0.72 \\
\hline Sex: male, $n(\%)$ & $66 / 79(83.5)$ & $38 / 43(88.4)$ & $28 / 36(77.8)$ & 0.69 \\
\hline Comorbidities $\geq 2, n(\%)$ & $18 / 79(22.8)$ & 9/43 (20.9) & $9 / 36(25.0)$ & 0.66 \\
\hline Fever, $n(\%)$ & $75 / 79(94.9)$ & $42 / 42(100)$ & $32 / 36(91.4)$ & 0.052 \\
\hline Dyspnea, $n(\%)$ & $42 / 78(54.5)$ & $25 / 42(59.5)$ & $16 / 36(45.7)$ & 0.22 \\
\hline Pneumonia, $n(\%)$ & $77 / 79(97.5)$ & $43 / 43(100)$ & $33 / 35(94.3)$ & 0.11 \\
\hline $\begin{array}{l}\mathrm{pO}_{2} / \mathrm{FiO}_{2}<200 \mathrm{~mm} \mathrm{Hg} \\
\text { at baseline No. (\%) }\end{array}$ & $32 / 79(40.5)$ & $22 / 43(51.2)$ & $10 / 36(27.8)$ & 0.035 \\
\hline ICU, $n(\%)$ & $41 / 79(51.9)$ & $41 / 43(95.3)$ & $0 / 36(0)$ & \\
\hline $\begin{array}{l}\text { White blood cells, median (IQR) } \\
\left.\text { [cells } / \mathrm{mm}^{2}\right]\end{array}$ & $\begin{array}{c}7290.0 \\
(5395.0-10590.0)\end{array}$ & $\begin{array}{c}8620.0 \\
(6680.0-11460.0)\end{array}$ & $\begin{array}{c}6415.0 \\
(4822.5-8010.0)\end{array}$ & 0.006 \\
\hline $\begin{array}{l}\text { Neutrophil-lymphocyte ratio, } \\
\text { median (IQR) }\end{array}$ & $7.6(3.9-12.8)$ & $11.7(7.6-16.2)$ & $4.2(2.6-7.6)$ & $<0.0001$ \\
\hline Hb, median (IQR) [g/dl] & $12.7(11.3-14.0)$ & $12.6(11.1-13.9)$ & $13.1(11.8-14.3)$ & 0.13 \\
\hline PLT, median (IQR), [× 1000/mm²] & $207.0(158.5-321.5)$ & $201.0(257.0-302.0)$ & $236.0(159.8-339.8)$ & 0.73 \\
\hline Albumin, median (IQR) [g/dl] & $3.1(2.7-3.4)$ & $2.9(2.7-3.3)$ & $3.3(3.1-3.6)$ & 0.0017 \\
\hline $\begin{array}{l}\text { Lactate dehydrogenase, median } \\
(\mathrm{IQR})[\mathrm{U} / \mathrm{I}]\end{array}$ & $331.0(243.8-437.3)$ & $369.0(297.0-455.0)$ & $265.0(210.5-342.5)$ & 0.001 \\
\hline CPK median (IQR) [U/I] & $77.0(50.0-200.0)$ & $91.0(42.0-325.0)$ & $74.0(50.0-153.0)$ & 0.46 \\
\hline $\begin{array}{l}\text { Creatinine, median (IQR) } \\
{[\mathrm{mg} / \mathrm{dl}]}\end{array}$ & $1.0(0.7-1.1)$ & $0.9(0.7-1.2)$ & $1.0(0.8-1.1)$ & 0.38 \\
\hline Ferritin, median (IQR) [ng/ml] & $892.4(547.7-1342.5]$ & $1101(649.1-1381.5]$ & $602.4(435.5-1026.3]$ & 0.019 \\
\hline CRP, mean (SD) [mg/dl] & $13.6(10.0)$ & $16.2(9.9)$ & $10.3(9.3)$ & 0.009 \\
\hline $\mathrm{PCT}$, median (IQR) $[\mathrm{ng} / \mathrm{ml}]$ & $0.3(0.1-0.7)$ & $0.5(0.3-1.2]$ & $0.2(0.1-0.3)$ & $<0.0001$ \\
\hline D-dimer, median (IQR) [ng/ml] & $1547.0(816.5-3215.5)$ & $1727.0(1139.8-4820.5)$ & $845.0(498.5-1877.5)$ & 0.017 \\
\hline Fibrinogen, median (IQR) $[\mathrm{mg} / \mathrm{ml}]$ & $591.0(523.5-651.5)$ & $603.0(539.5-663.5)$ & $1177.0(671.0-1879.0)$ & 0.36 \\
\hline
\end{tabular}


$\mathrm{NLR}, \mathrm{P} / \mathrm{F}<200 \mathrm{~mm} \mathrm{Hg}$, LDH and serum ferritin, transforming the latter variable into categorical (the Youden index or optimal threshold value of serum ferritin was $>940 \mathrm{ng} / \mathrm{ml})$. We found that NLR correlates with a severe disease outcome $(p=0.03)$. The model is representative of reality: the HL test was not significant, $p=0.1$ (Table IV).

\section{In-hospital mortality}

Eighteen patients (22.7\%) died during hospitalization (Table II). The median age was 69.3 years.

In univariate analysis the following differences between survivor and non-survivor patients were significant: dyspnea $(p=0.0083)$, admission to ICU $(p=0.0002)$, NLR $(p=0.0006)$ and hemoglobin $(p=0.02)$ (Table II). In multivariate analysis, transforming the serum ferritin into a categorical variable (>1157 ng/ml), only NLR was associated with in-hospital mortality $(p=0.03)$. The model is representative of reality ( $\mathrm{HL}, p=0.3$ ) (Table IV).
Critical progression for patients with $\mathrm{PaO}_{2} / \mathrm{FiO}_{2} \geq 200 \mathrm{~mm} \mathrm{Hg}$ and $\mathrm{PaO}_{2} / \mathrm{FiO}_{2}$ $<200 \mathrm{~mm} \mathrm{Hg}$

In Table III data on critical progression of patients with $P / F \geq 200 \mathrm{~mm} \mathrm{Hg}$ are summarized.

Forty-seven out of 79 patients had a P/F $\geq 200 \mathrm{~mm} \mathrm{Hg}$ at baseline and 21 of them developed a critical illness during hospitalization (44.7\%). The in-hospital mortality rate in this group was $19.1 \%(9 / 47)$.

We evaluated which variables were correlated with critical COVID-19 in this subgroup of $47 \mathrm{pa}$ tients. In univariate analysis, WBC count $(p=0.019)$ $\operatorname{NLR}(p<0.0001), \operatorname{LDH}(p=0.017)$, serum ferritin ( $p$ $=0.011)$ and CRP $(p=0.029)$ and PCT $(p=0.0013)$ correlated significantly with critical COVID-19 in patients with $P / F \geq 200 \mathrm{~mm} \mathrm{Hg}$ at hospital admission.

Multiple logistic regression was performed including the following variables: white blood

Table II. Demographic, clinic and laboratory characteristics of patients referred to the "in-hospital mortality" outcome

\begin{tabular}{|c|c|c|c|c|}
\hline \multirow[t]{2}{*}{ Parameter } & \multirow[t]{2}{*}{ Total population } & \multicolumn{2}{|c|}{ In-hospital mortality } & \multirow[t]{2}{*}{$P$} \\
\hline & & Yes & No & \\
\hline$N(\%)$ & 79 & 18 & 59 & \\
\hline Age [years], mean (SD) [range] & 65.5 (10.6) [32.2-87.6] & $69.3(8.6)$ [51.6-87.6] & $64.5(11.1)[32.2-84.8]$ & 0.12 \\
\hline Sex: male, $n(\%)$ & $66 / 79(83.5)$ & $17 / 18(94.4)$ & 47/59 (79.7) & 0.14 \\
\hline Comorbidities $\geq 2, n(\%)$ & $18 / 79(22.8)$ & $6 / 18(33.3)$ & $11 / 58(19.0)$ & 0.19 \\
\hline Fever, $n(\%)$ & $75 / 79(94.9)$ & $18 / 18(100.0)$ & $55 / 58(94.8)$ & 0.20 \\
\hline Dyspnea, $n(\%)$ & $42 / 78(54.5)$ & $12 / 18(66.7)$ & $30 / 58(51.7)$ & 0.0083 \\
\hline Pneumonia, $n(\%)$ & $77 / 79(97.5)$ & $18 / 18(100.0)$ & $57 / 59(96.6)$ & 0.42 \\
\hline $\begin{array}{l}\mathrm{pO}_{2} / \mathrm{FiO}_{2}<200 \mathrm{~mm} \mathrm{Hg} \\
\text { at baseline, } n(\%)\end{array}$ & $32 / 79(40.5)$ & $9 / 18(50.0)$ & $22 / 59(37.3)$ & 0.34 \\
\hline ICU, $n(\%)$ & $41 / 79(51.9)$ & $16 / 18(88.9)$ & $23 / 59(39.0)$ & 0.0002 \\
\hline $\begin{array}{l}\text { White blood cells, median (IQR) } \\
\left.\text { [cells } / \mathrm{mm}^{2}\right]\end{array}$ & $\begin{array}{c}7290.0[5395.0- \\
10590.0]\end{array}$ & $\begin{array}{c}8845.0[6675.0- \\
11222.5]\end{array}$ & $\begin{array}{c}7100.0[5225.0- \\
10480.0]\end{array}$ & 0.16 \\
\hline $\begin{array}{l}\text { Neutrophil-lymphocyte ratio, } \\
\text { median (IQR) }\end{array}$ & $7.6[3.9-12.8]$ & $12.3[8.3-21.5]$ & $6.0[3.6-12.1]$ & 0.0006 \\
\hline $\mathrm{Hb}$, median $(\mathrm{IQR})[\mathrm{g} / \mathrm{dl}]$ & $12.7[11.3-14.0]$ & $12.0[9.9-13.0]$ & $12.8[11.6-14.2]$ & 0.02 \\
\hline PLT, median (IQR), $\left[\times 1000 / \mathrm{mm}^{2}\right]$ & $207.0[158.5-321.5]$ & $195.0[154.5-302.0]$ & $223.0[161.5-341.5]$ & 0.77 \\
\hline Albumin, median (IQR) $[\mathrm{g} / \mathrm{dl}]$ & $3.1[2.7-3.4]$ & $2.9[2.6-3.2]$ & $3.1[2.8-3.4]$ & 0.09 \\
\hline $\begin{array}{l}\text { Lactate dehydrogenase, } \\
\text { median (IQR) }[\mathrm{U} / \mathrm{I}]\end{array}$ & $331.0[243.8-437.3]$ & $380.0[299.5-455.8]$ & $303.0[243.8-415.0]$ & 0.11 \\
\hline CPK median (IQR) [U/I] & $77.0[50.0-200.0]$ & $70.0[34.0-148.5]$ & $83.5[51.3-223.0]$ & 0.49 \\
\hline Creatinine, median (IQR) [mg/dl] & $1.0[0.7-1.1]$ & $1.0[0.7-1.6]$ & $0.9[0.7-1.1]$ & 0.50 \\
\hline Ferritin, median (IQR) [ng/ml] & $892.4[547.7-1342.5]$ & $1246.0[691.3-1388.3]$ & $776.6[547.7-1323.5]$ & 0.25 \\
\hline $\mathrm{RCP}$, mean (SD) [mg/dl] & $13.6(10.0)$ & $14.5(10.2)$ & $13.3(10.0)$ & 0.63 \\
\hline PCT, median (IQR) $[\mathrm{ng} / \mathrm{ml}]$ & $0.3[0.1-0.7]$ & $0.5[0.3-1.2]$ & $0.3[0.1-0.6]$ & 0.10 \\
\hline D-dimer, median (IQR) [ng/ml] & $1547.0[816.5-3215.5]$ & $1998.0[1080.0-6388.0]$ & $1488.5[774.8-2310.8]$ & 0.20 \\
\hline Fibrinogen, median (IQR) [mg/ml] & $591.0[523.5-651.5]$ & $597.5[521.3-669.0]$ & $593.0[530.0-648.0]$ & 0.98 \\
\hline
\end{tabular}

$I C U$ - intensive care unit, $H b$ - hemoglobin, PLT - platelets, CPK - creatine phosphokinase, CRP - C-reactive protein, PCT - procalcitonin, $I Q R$ - interquartile range, $S D$ - standard deviation 
cells, neutrophils/lymphocyte ratio, ferritin as a categorical variable (> $1006 \mathrm{ng} / \mathrm{ml}$ ), C-reactive protein, and serum lactate dehydrogenase. As shown in Table IV, the only variable significantly associated with critical illness in this sub group was ferritin values $\geq 1006 \mathrm{ng} / \mathrm{ml}$ ( $p=$ $0.02)$. The model is representative of reality $(\mathrm{HL}$, $p=0.3)$.

Thirty-two patients had a $\mathrm{P} / \mathrm{F}_{2}<200 \mathrm{~mm} \mathrm{Hg}$ at baseline and 22 needed invasive ventilation during hospitalization (68.7\%). The hospital mortality rate in this group was $28 \%(9 / 32)$.

In univariate analysis, NLR, LDH and PCT values were significantly associated with progression ( $p=0.03 ; p=0.036 ; p=0.02$ respectively). None of these variables were associated with critical COVID-19 in multivariate logistic regression (Table IV).

\section{Discussion}

COVID-19 infection is characterized by a wide range of clinical expression, ranging from asymptomatic to mild forms with involvement of the upper airways, to moderate or severe features of pneumonia, to critical forms with ARDS, derangement of hemostasis, and viral sepsis [1]. However, usually, the disease does not appear at the onset in its full expression but it progresses over two to three weeks, during which the maximum viral replication of the first week is replaced by a condition of a severe inflammatory state which conditions the disease severity, even leading to death. Several studies have reported risk factors associated with the development of critical illness: Wu et al. reported that risk factors associated with development of ARDS and death included older age, neutrophilia, organ dysfunction, coagulopathy and elevated D-dimer levels [12]. Wenhua et al. developed a clinical risk score and validated a webbased risk calculator based on 10 variables commonly measured on admission to the hospital, to predict the development of critical illness among hospitalized COVID-19 infected patients [13]. In hospitalized patients with respiratory distress, Brandon et al. recommend that clinicians closely monitor WBC count, lymphocyte count, platelet count, IL-6 and serum ferritin as markers for potential progression to critical illness [14].

Table III. Demographic, clinic and laboratory characteristics of patients with PO2/FiO2 >= $200 \mathrm{mmHg}$ at admission with and without progression

\begin{tabular}{|c|c|c|c|c|}
\hline \multirow[t]{2}{*}{ Parameter } & \multirow{2}{*}{$\begin{array}{c}\text { Total of patients } \\
\text { with } \mathrm{PO}_{2} / \mathrm{FiO}_{2} \geq 200 \\
\text { at admission }\end{array}$} & \multicolumn{2}{|c|}{ Critical } & \multirow[t]{2}{*}{$P$} \\
\hline & & Yes & No & \\
\hline$N(\%)$ & 47 & 21 & 26 & \\
\hline Age [years], mean (SD) [range] & 64.9 (10.9) [32.2-84.8] & $66.2(9.3)[46.7-77.5]$ & $63.8(12.1)[32.2-84.8]$ & 0.45 \\
\hline Sex: male, $n(\%)$ & $39 / 47(83.0)$ & $19 / 21(90.5)$ & 20/26 (76.9) & 0.21 \\
\hline Comorbidities $\geq 2, n(\%)$ & $10 / 47(21.3)$ & $3 / 21(14.3)$ & $7 / 26(26.9)$ & 0.29 \\
\hline Fever, $n(\%)$ & 45/47 (95.7) & $21 / 21(100)$ & $24 / 26(92.3)$ & 0.19 \\
\hline Dyspnea, $n(\%)$ & $23 / 47(48.9)$ & $12 / 21(57.1)$ & $11 / 26(42.3)$ & 0.31 \\
\hline Pneumonia, $n(\%)$ & $45 / 47(95.7)$ & $21 / 21(100)$ & $24 / 26(92.3)$ & 0.19 \\
\hline $\begin{array}{l}\text { White blood cells, median (IQR), } \\
\left.\text { [cells } / \mathrm{mm}^{2}\right]\end{array}$ & $\begin{array}{c}6760.0 \\
{[5135.0-9670.0]}\end{array}$ & $\begin{array}{c}9180.0 \\
{[5400.0-11520.0]}\end{array}$ & $\begin{array}{c}5685.0 \\
{[4667.5-7552.5]}\end{array}$ & 0.019 \\
\hline $\begin{array}{l}\text { Neutrophil-lymphocyte ratio, } \\
\text { median (IQR) }\end{array}$ & $6.8[4-12.5]$ & $11.7[7.6-13.8]$ & $4.5[2.5-7.0]$ & $<0.0001$ \\
\hline $\mathrm{Hb}$, mean (SD) [g/dl] & $12.8(1.9)$ & $12.6(2.2)$ & $13.0(1.6)$ & 0.48 \\
\hline PLT, median $(\mathrm{IQR})\left[\times 1000 / \mathrm{mm}^{2}\right]$ & $223.0[150.0-317.5]$ & $227.0[148.0-323.0]$ & $217.5[157.3-314.0]$ & \\
\hline $\begin{array}{l}\text { Lactate dehydrogenase, median } \\
(\mathrm{IQR})[\mathrm{U} / \mathrm{I}]\end{array}$ & $325.0[231.0-402.0]$ & $379.5[326.5-471.5]$ & $251.0[207.0-345.0]$ & 0.017 \\
\hline CPK median (IQR) [U/I] & $90.0[54.8-200.3]$ & $93.0[63.5-362.8]$ & $83.0[50.8-158.5]$ & 0.47 \\
\hline Creatinine, median (IQR) [mg/dl] & $0.9[0.8-1.1]$ & $0.8[0.7-1.1]$ & $1.1[0.8-1.1]$ & \\
\hline Ferritin, median (IQR) [ng/ml] & $784.1[539.1-1375.0]$ & $1217.0[748.8-1444.0]$ & $592.3[415.4-921.4]$ & 0.011 \\
\hline RCP, median (IQR) [mg/dl] & $10.6[4.4-19.1]$ & $16.5[6.9-20.9]$ & $6.3[2.8-15.4]$ & 0.029 \\
\hline PCT, median (IQR) [ng/ml] & $0.3[0.2-0.7]$ & $0.5[0.4-1.0]$ & $0.2[0.1-0.3]$ & 0.0013 \\
\hline D-dimer, median (IQR) [ng/ml] & 1419.5 [701.0-2980.5] & $1524.0[673.8-5137.8]$ & $1163.5[667.0-1817.5]$ & \\
\hline Fibrinogen, median (IQR) $[\mathrm{mg} / \mathrm{ml}]$ & $591.0[528.0-623.0]$ & $603.0[569.5-629.5]$ & $591.0[523.8-623.0]$ & \\
\hline
\end{tabular}

$I C U$ - intensive care unit, $\mathrm{Hb}$ - hemoglobin, PLT - platelets, CPK - creatine phosphokinase, CRP - C-reactive protein, $P C T$ - procalcitonin, $I Q R$ - interquartile range, $S D$ - standard deviation 
Table IV. Multivariate logistic regression analyses

\begin{tabular}{|c|c|}
\hline Outcome: critical COVID-19 & Multivariate logistic regression \\
\hline Neutrophil-lymphocyte ratio, OR $(95 \% \mathrm{Cl}, p)$ & $1.1(1.0-1.2,0.03)$ \\
\hline $\mathrm{PO}_{2} / \mathrm{FiO}_{2}<200 \mathrm{~mm} \mathrm{Hg}$ at baseline, OR $(95 \% \mathrm{Cl}, p)$ & $2.4(0.8-7.4,0.11)$ \\
\hline Ferritin > 940.1, OR $(95 \% \mathrm{Cl}, p)$ & $3.0(0.9-9.6,0.06)$ \\
\hline Lactate dehydrogenase, OR $(95 \% \mathrm{Cl}, p)$ & $1.0(0.99-1.0,0.6)$ \\
\hline AUROC (STD, 95\% CI) & $0.8(0.05 ; 0.7-0.9,<0.0001)$ \\
\hline $\mathrm{HL}(p)$ & $13.4(0.1)$ \\
\hline \multicolumn{2}{|l|}{ Outcome: in-hospital mortality for COVID-19 } \\
\hline Dyspnea, OR $(95 \% \mathrm{Cl}, p)$ & $1.4(0.4-5.0,0.5)$ \\
\hline Neutrophil-lymphocyte ratio, OR $(95 \% \mathrm{Cl}, p)$ & $1.1(1.0-1.2,0.03)$ \\
\hline Hemoglobin, OR $(95 \% \mathrm{Cl}, p)$ & $0.7(0.5-1,0.07)$ \\
\hline Ferritin > 1157.0, OR $(95 \% \mathrm{Cl}, p)$ & $2.3(0.7-8.5,0.19)$ \\
\hline AUROC (STD, 95\% Cl, p) & $0.8(0.07,0.7-0.9,0.0002)$ \\
\hline $\mathrm{HL}(p)$ & $7.6(0.5)$ \\
\hline \multicolumn{2}{|l|}{$\begin{array}{l}\text { Outcome: critical COVID-19 in patients } \\
\text { with } \mathrm{pO}_{2} / \mathrm{FiO}_{2}>200 \mathrm{~mm} \text { Hg at hospital admission }\end{array}$} \\
\hline White blood cells, OR $(95 \% \mathrm{Cl}, p)$ & $1.1(0.9-1.5,0.2)$ \\
\hline Neutrophil-lymphocyte ratio, OR $(95 \% \mathrm{Cl}, p)$ & $1.1(1.0-1.2,0.4)$ \\
\hline Ferritin > 1006, OR $(95 \% \mathrm{Cl}, p)$ & $6.0(1.3-30.6,0.02)$ \\
\hline CRP, OR $(95 \% \mathrm{Cl}, p)$ & $1.0(1.0-1.1,0.4)$ \\
\hline Lactate dehydrogenase, OR $(95 \% \mathrm{Cl}, p)$ & $1.0(0.99-1.00,0.9)$ \\
\hline AUROC (STD, 95\% Cl, p) & $0.9(0.06,0.8-1.0,<0.0001)$ \\
\hline $\mathrm{HL}(p)$ & $9.7(0.3)$ \\
\hline \multicolumn{2}{|l|}{$\begin{array}{l}\text { Outcome: critical COVID-19 in patients } \\
\text { with } \mathrm{pO}_{2} / \mathrm{FiO}_{2}<200 \mathrm{~mm} \text { Hg at hospital admission }\end{array}$} \\
\hline Neutrophil-lymphocyte ratio, OR $(95 \% \mathrm{Cl}, p)$ & $1.1(1.0-1.3,0.09)$ \\
\hline Lactate dehydrogenase, OR $(95 \% \mathrm{Cl}, p)$ & $1.0(0.99-1.02,0.12)$ \\
\hline AUROC (STD, 95\% Cl, p) & $0.8(0.09,0.6-1,0.008)$ \\
\hline $\mathrm{HL}(p)$ & $12.0(0.2)$ \\
\hline
\end{tabular}

operating characteristics, $\mathrm{HL}-$ Hosmer-Lemeshow test, $C R P-C$ reactive protein

In our study we evaluated standard validated biomarkers at the time of admission in COVID-19 positive patients, but we used clinical criteria in dividing patients into two groups both at baseline ( \pm ARDS moderate/severe) and for clinical progression ( \pm ICU/death). Our population, of not advanced average age, was made up of $40 \%$ of subjects with a severe picture (therefore suggestive of the disease having already progressed towards an inflammatory phase) and $60 \%$ with a milder or more recent form. Overall, over $54 \%$ of the patients required intensive ventilation, $69 \%$ of those with ARDS at onset, $44 \%$ of those with a milder form at the time of hospitalization; in addition, $28 \%$ of patients with baseline ARDS and $19 \%$ of the others died. We found that patients with a critical course of COVID-19 illness showed median values of WBC count, NLR, LDH, serum ferritin, CRP, PCT and D-dimer higher than those who had a non-critical course and only NLR correlated with both the pro- gression towards invasive ventilation and mortality.

However, in patients with a not particularly severe form $(P / F \geq 200 \mathrm{~mm} \mathrm{Hg})$ only serum ferritin was a significant predictive value of disease progression.

Therefore, our study reveals two main laboratory characteristics as predictive risk factors of critical illness and death: NLR and serum ferritin. Both are expressions of a systemic inflammatory response that tends to escalate toward a cytokine storm.

Neutrophil/lymphocyte ratio is reported as having great value indicating a patient's overall inflammatory status [15] and it is considered a risk factor of mortality for many diseases other than infections $[16,17]$. Ferritin is a blood protein that contains iron and is used as a marker of iron deficiency. However, it arises from damaged cells [18] and its synthesis is induced in animal models by inflammation [19]. Therefore, serum ferritin is a wellknown acute-phase reactant, with levels that mirror the degree of acute and chronic inflammation 
in infectious, rheumatologic, hematologic and malignant disease. In adult onset Still's disease high serum ferritin levels are an important diagnostic tool [20]. Unlike many bacterial infections, viral infections are commonly characterized by elevated levels of the pro-inflammatory cytokine IL-18 and increased circulating ferritin concentrations [21].

In our whole population NLR is proposed as an independent predictive factor for the risk of progression to invasive ventilation and death, confirming other experiences with COVID-19 infection [22-24]. However, it does not achieve statistical significance if the analysis is carried out on all the population at an earlier or the milder phase.

A high NLR has already been reported in SARS-COV [25, 26], in MERS [27], and in severe RSV infections [28]; lymphopenia and neutrophilia have also been reported in Ebola [29]. Viral infections such as SARS, RSV and Ebola are characterized by a great inflammatory response but are also debilitating diseases, and inevitably lead to activation of the hypothalamic-pituitary-adrenal (HPA) axis and excess cortisol secretion [30].

The massive phlogistic response with TNF, IL-1 $\beta$, IL-6, IL-18 and GMCSF that stimulates neutrophils and macrophages tends to be counter-regulated by IL-4, IL-10, IL-1RA and by cortisol production [29-33].

This leads to an increase of neutrophils, a decrease of lymphocytes, and an increase in NLR. Lymphopenia and neutrophilia in SARS were related to the prevailing serum cortisol [34], which probably reflected the integrity of the HPA axis and a stress response [33-35].

In addition, cortisol seems, on the one hand, to promote the apoptosis of lymphocytes, and on the other to counter-regulate the apoptosis of neutrophils [36].

In our study serum ferritin levels were not in the normal range $(30-400 \mathrm{ng} / \mathrm{ml})$ in the whole COVID-19 population, both in non-severe and severe disease, although they were more elevated in patients with ARDS. These data are in accordance with those reported in international literature and prompt the suggestion that COVID-19 may be the fifth member of hyper-ferritinemic syndromes so far comprising four clinical entities: septic shock, macrophage activation syndrome (MAS), Still's disease in adults (AOSD) and catastrophic antiphospholipid syndrome (CAPS). All these diseases are characterized by both an extremely elevated serum ferritin level and partly life-threatening hyperinflammation [37].

In our population, the evaluation of ferritin as a predictive factor of progression towards invasive ventilation and death has given contradictory answers. Only univariate analysis demonstrated serum ferritin as a predictor of disease progression, not of death. Nevertheless, in the patient group with $P / F \geq 200$ it was a strong predictor of progression (median levels of $1217 \mathrm{ng} / \mathrm{ml}$ vs. $592 \mathrm{ng} / \mathrm{ml}$ in critical vs. non-critical course) both in univariate and multivariate logistic regression analysis considering levels $>940 \mathrm{ng} / \mathrm{ml}$. However, focusing attention only on patients with $P / F \geq 200$ at hospital admission, ferritin levels $>1006 \mathrm{ng} / \mathrm{ml}$ were the only predictive factor of progression also for multivariate logistic regression.

In conclusion, the study of a small cohort does not allow definitive conclusions to be drawn and needs validation in a much wider case study. While on the one hand the insufficiency of ventilation on admission already places the medical staff on clinical alert, in less severe patients the dosage of ferritin, also accompanied by NLR, can be a reason to activate strategies focused on the control of systemic inflammation.

\section{Acknowledgments}

We thank Prof. Stefano Ricci for his important editorial assistance.

\section{References}

1. Yuki K, Fujiogi M, Koutsogiannaki S. COVID-19 pathophysiology: a review. Clin Immunol 2020; 215: 108427.

2. Huang C, Wang Y, Li X, et al. Clinical features of patients infected with 2019 novel coronavirus in Wuhan, China. Lancet 2020; 395: 497-506.

3. Yufang S, Ying W, Changshun S, et al. COVID-19 infection: the perspectives on immune responses. Cell Death Differ 2020; 27: 1451-4.

4. Chen N, Min Z, Xuan D, et al. Epidemiological and clinical characteristics of 99 cases of 2019 novel coronavirus pneumonia in Wuhan, China: a descriptive study. Lancet 2020; 395: 507-13.

5. Wang F, Hou H, Luo Y, et al. The laboratory tests and host immunity of COVID-19 patients with different severity of illness. JCl Insight 2020; 5: e137799.

6. Papazafiropoulou AK, Antonopoulos S. The COVID-19 pandemic and diabetes mellitus. Arch Med Sci Atheroscler Dis 2020; 5: e200-5.

7. Rethemiotaki I. A preliminary study of coronavirus disease 2019 in China: the impact of cardiovascular disease on death risk Arch Med Sci Atheroscler Dis 2020; 5: e219-23.

8. Papazian L, Aubron C, Brochard L, et al. Formal guidelines: management of acute respiratory distress syndrome. Ann Intensive Care 2019; 9: 69.

9. Metlay JP, Waterer GW, Long AC, et al. Diagnosis and treatment of adults with community-acquired pneumonia. an official clinical practice guideline of the American Thoracic Society and Infectious Diseases Society of America. Am J Respir Crit Care Med 2019; 200: e45-e67.

10. Gao HN, Lu HZ, Cao B, et al. Clinical findings in 111 cases of influenza A (H7N9) virus infection. N Engl J Med 2013; 368: 2277-85.

11. Habibzadeh F, Habibzadeh P, Yadollahie M. On determining the most appropriate test cut-off value: the case of tests with continuous results. Biochem Med (Zagreb) 2016; 26: 297-307. 
12. Wu C, Chen X, Cai Y, et al. Risk factors associated with acute respiratory distress syndrome and death in patients with coronavirus disease 2019 pneumonia in Wuhan, China. JAMA Intern Med 2020; 180: 934-43.

13. Liang W, Liang $\mathrm{H}, \mathrm{Ou}$ L, et al. Development and validation of a clinical risk score to predict the occurrence of critical illness in hospitalized patients with COVID-19. JAMA Intern Med 2020; 180: 1081-9.

14. Henry BM, Santos de Oliveira MH, Benoi S, Plebania M, Lippia G. Hematologic, biochemical and immune biomarker abnormalities associated with severe illness and mortality in coronavirus disease 2019 (COVID-19) a meta-analysis. Clin Chem Lab Med 2020; 58: 1021-8.

15. Faria SS, Fernandes PC, Barbosa Silva MJ, et al. The neutrophil-to-lymphocyte ratio: a narrative review. Ecancermedicalscience 2016; 10: 702.

16. Azab B, Zaher M, Weiserbs KF, Torbey E, et al. Usefulness of neutrophil to lymphocyte ratio in predicting shortand long-term mortality after non-ST-elevation myocardial infarction. Am J Cardiol 2010; 106: 470-6.

17. Guthrie GJ, Charles KA, Roxburgh CS, Horgan PG, McMillan DC, Clarke SJ. The systemic inflammation-based neutrophil-lymphocyte ratio: experience in patients with cancer. Crit Rev Oncol Hematol 2013; 88: 218-30.

18. Kell DB, Pretorius E. Serum ferritin is an important inflammatory disease marker, as it is mainly a leakage product from damaged cells. Metallomics 2014; 6: 748-73.

19. Konijn AM, Hershko C. Ferritin synthesis in inflammation. I. Pathogenesis of impaired iron release. Br J Haematol 1977; 37: 7-16.

20. Meijvis SC, Endeman H, Geers AB, ter Borg EJ.Extremely high serum ferritin levels as diagnostic tool in adult-onset Still's disease. Neth J Med 2007; 65: 212-4.

21. Slaats J, Ten Oever J, van de Veerdonk FL, Netea MG. IL-1 $\beta /$ IL-6/CRP and IL-18/ferritin: Distinct Inflammatory Programs in Infections. PLoS Pathog 2016; 12: e1005973.

22. Qin C, Zhou L, Hu Z, et al. Dysregulation of immune response in patients with coronavirus 2019 (COVID-19) in Wuhan, China. Clin Infect Dis 2020; 71: 762-8.

23. Yang AP, Liu JP, Tao WQ, Li HM. The diagnostic and predictive role of NLR, d-NLR and PLR in COVID-19 patients. Int Immunopharmacol 2020; 84: 106504

24. Yuwei L, Xuebei D, Jing C, et al. Neutrophil-to-lymphocyte ratio as an independent risk factor for mortality in hospitalized patients with COVID-19. J Infect 2020; 81: e6-e12.

25. Lee $\mathrm{N}$, Hui D, Wu A, et al. A major outbreak of severe acute respiratory syndrome in Hong Kong. New Engl J Med 2003; 348: 1986-94.

26. Booth CM, Matukas LM, Tomlinson GA, et al. Clinical features and short-term outcomes of 144 patients with SARS in the greater Toronto area. JAMA 2003; 289: 2801-9.

27. Min CK, Cheon S, Ha NY, et al. Comparative and kinetic analysis of viral shedding and immunological responses in MERS patients representing a broad spectrum of disease severity. Sci Rep 2016; 6: 25359.

28. O’Donnell DR, Carrington D. Peripheral blood lymphopenia and neutrophilia in children with severe respiratory syncytial virus disease. Pediatr Pulmonol 2002; 34: 128-30.

29. Leroy EM, Baize S, Debre P, Lansoud-Soukate J, Mavoungou E. Early immune responses accompanying human asymptomatic Ebola infections. Clin Exp Immunol 2001; 124: 453-60.

30. Panesar NS. What caused lymphopenia in SARS and how reliable is the lymphokine status in glucocorticoid-treated patients? Med Hypotheses 2008; 71: 298-301.
31. Perlman S, Dandekar AA. Immunopathogenesis of coronavirus infections: implications for SARS. Nat Rev Immunol 2005; 5: 917-27.

32. Gu J, Gong E, Zhang B, et al. Multiple organ infection and the pathogenesis of SARS. J Exp Med 2005; 202: 415-24.

33. Panesar NS. Lymphopenia in SARS. Lancet 2003; 361: 1985.

34. Panesar NS, Lam CW, Chan MH, Wong CK, Sung JJ. Lymphopenia and neutrophilia in SARS are related to the prevailing serum cortisol. Eur J Clin Invest 2004; 34 382-4.

35. Panesar NS. Lymphopenia in SARS: apoptosis definitely is involved, but is it glucocorticoid or virus induced? BMJ 2003; 327: 620

36. Cameron RG, Black PN, Braan C, Browett PJ. A comparison of the effects of oral prednisone and inhaled beclomethasone dipropionate on circulating leukocytes. Aust N Z J Med 1996; 26: 800-5.

37. Kappert K, Jahić A, Tauber R. Assessment of serum ferritin as a biomarker in COVID-19: bystander or participant? Insights by comparison with other infectious and non-infectious diseases. Biomarkers 2020; 25: 616-25. 